Discussion Paper No. $\quad 576$

\title{
WHEN SHOULD A CAT INDEX FUTURES
} BE CREATED?

\author{
Kazuhiko Ōhashi
}

March 2003

The Institute of Social and Economic Research Osaka University

6-1 Mihogaoka, Ibaraki, Osaka 567-0047, Japan 


\title{
When should a CAT index futures be created?
}

\author{
Kazuhiko Ōhashi \\ Graduate School of \\ International Corporate Strategy, \\ Hitotsubashi University*
}

First draft: August 2002

This draft: March 2003

\begin{abstract}
Traditionally, insurance risks are borne in reinsurance markets. In 1990s, however, after the sequence of huge natural disasters and huge insurance payments, the reinsurance markets reduced its capability to bear risks, especially those related to catastrophic natural disasters. CatastropheLinked Securities (CLS) were invented in order to fill the need for additional reinsurance capacity by transferring insurance risks to the capital markets. The CAT (catastrophe) index futures is one of the several types of CLS's. This paper investigates conditions under which the index derivatives, such as the CAT index futures, of the insurance risks can be traded by the non-insurance investors and is beneficial from the insurers' and the exchange's viewpoints.
\end{abstract}

*I thank Yoshiyasu Ono, Fumio Ohtake, Shinsuke Ikeda, Masaki Aoyagi, Atsushi Tsuneki, Atsushi Kajii, Daiji Kawaguchi and all seminar participants at the ISER, Osaka University. This paper is still preliminary. Comments are very welcome. (e-mail: kohashi@ics.hit-u.ac.jp) 


\section{INTRODUCTION}

Insurance risks are traditionally borne in reinsurance markets. That is, after originating insurance contracts and bearing risks of customers, the insurers spread and reallocate such insurance risks among themselves and reinsurers. Lloyd's is a notable example. Munich Re. and Swiss Re. are some of the representative reinsurers.

In 1990's, however, the capability of the reinsurance markets to bear risks was at stake. A sequence of huge natural disasters, including Hurricane Andrew (1992) and Northridge Earthquake (1994), produced huge amount, more than $\$$ 30 billion just for Hurricane Andrew and Northridge Earthquake, in industrywide insured losses. There was the need for additional reinsurance capacity. Capital markets, or the non-insurance investors in them, became the natural target. (See Ganapati et. al. (1997).)

Then, innovation occurred. Catastrophe-linked securities (CLS's) were created, which enabled the investors outside the insurance and reinsurance industry to trade the catastrophe insurance risks, so that the capital markets could provide additional capacity for bearing the insurance risks. A CAT (catastrophe) index futures contract is among the several types of CLS's. ${ }^{1}$

The CAT index futures was introduced by Chicago Board of Trade (CBOT) in 1992, based on an index provided by the Insurance Services Office (ISO). Since 1995, the index has been changed to that provided by Property Claims Services (PCS), which is now regarded as the industry accepted standards. Other indexes are used in other markets. In the Bermuda Commodity Exchange (BCOE), CAT index derivative instruments are based on the Guy Carpenter Catastrophe Index (GCCI). In over-the-counter (OTC) markets, Risk Management Solutions (RMS) Index and Sigma Index by Swiss Re. are utilized. (See Kist and Meyers (1999).)

Roughly speaking, these indexes are designed to reflect the industry-wide insurance losses, not the individual insurer's losses. From the purpose of riskreallocation, such design of the indexes limits the hedging effectiveness of the CAT index derivatives for the individual insurers. The risk traded by the index is inevitably different from the risks that the individual insurers wish to hedge. There is basis risk. Thus, if the insurers and the investors outside the insurance industry have the same information about the insurance risks, there is no benefit for creating an index derivatives for both sides. Trading each insurer's risk

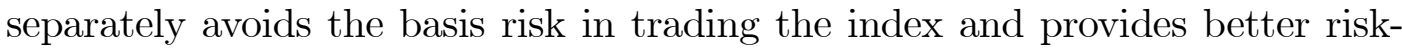
sharing opportunities.

\footnotetext{
${ }^{1}$ Securitization $\varnothing \mathrm{f}$ catastrophe insurance risks is another example.
} 
However, this is not the case for insurance risks, including catastrophe risk. Usually, the outside non-insurance investors know little about the risks that the insurance contracts deal with, while the insurers and the reinsurers know them well. Asymmetric information is prevalent between the insiders and the outsider of the insurance markets. Trading an index of insurance risks is expected to mitigate such asymmetric information and to facilitate the participation of the non-insurance investors in trading. (See Kist and Meyers (1999), and Major (1999).)

Despite such device, the CAT index derivative markets have not been successful. For all contracts, trading has been thin. The exchanges have shut down most of these markets. Although this is partly because of the recovery of capacity of the reinsurance markets due to the lack (and luck) in occurrence of huge natural disasters, from the theoretical viewpoint, the developments of the CAT index derivatives should be meaningful steps in achieving incremental risk transfer to the capital markets.

What was wrong? Under what condition, can the index derivatives, such as the CAT index futures, of the insurance risks be traded and preferred to the reinsurance contracts? These are the questions that we address in this paper.

In what follows, we focus on the situation where each insurance risk of each insurer cannot be traded separately with the non-insurance outside investors because of the adverse selection. As practical way to mitigate such adverse selection problem, we consider an index futures where the index is defined to be the average of the payoffs of the insurance risks that the individual insurers bear. We first investigate the condition under which bundling these risks into an index futures mitigates the adverse selection enough for the index futures to be traded between the insurers and the outside investor.

We then compare the attractiveness of the index futures with the reinsurance markets from the insurers' viewpoints. Participants in the reinsurance markets are presumably professionals in insurance. They know equally well about the insurance risks that they trade. Adverse selection problem about the insurance risks is small in the reinsurance markets. Thus, we model the reinsurance markets as one representative reinsurer who has the same information as the insurers, but is less risk tolerant than the representative non-insurance outside investor. We consider the idealized reinsurance markets where the insurers and the reinsurer have the symmetric information, trade their risks competitively, and attain the optimal risk allocation. We then investigate the condition under which each insurer, ex-ante, wish to trade the index futures rather than the reinsurance contracts.

We also investigate the attractiveness of creating the index futures from the 
exchange's viewpoint..

In section 2 , we formulate the model. In section 3 , we investigate the condition under which the index futures can be traded between the insurers and the outside non-insurance investors. In section 4, we investigate the idealized reinsurance markets. In section 5, we compare the ex-ante attractiveness of the index futures with the reinsurance contracts to the insurers. In section 6 , we investigate the attractiveness of the index futures from the exchange'ss viewpoint. In section 7 , we conclude with some comments on further investigation.

\section{THE MODEL}

All random variables are defined on a probability space $(\Omega, \mathcal{F}, P)$. Throughout we denote by $\operatorname{Var}[\chi]$, the unconditional variance of random variable $\chi$, and by $\operatorname{Var}[\chi \mid \eta]$, the conditional variance of $\chi$ given $\eta$. Similarly $\operatorname{Cov}[\chi, \xi]$ denotes the unconditional covariance between $\chi$ and $\xi$, and $\operatorname{Cov}[\chi, \xi \mid \eta]$ the conditional covariance.

There are $N+2$ agents, with von Neumann-Morgenstern utility functions displaying constant absolute risk aversion. We refer to the first $N$ agents insurers and assume that each insurer $n(n=1, \ldots, N)$ has an asset, as an insurance contract, which yields a stochastic payoff $z_{n}$ at some terminal date. The $N+$ 1st agent is an aggregated reinsurer who provides reinsurance for the insurers. The $N+2$ nd agent is an aggregated outside investor who represents the (noninsurance) capital market as a whole.

There are three dates in the economy. At the ex-ante stage, date 0 , the insurers decide which contract and with whom they trade at date 1, an index futures with the outside investors or reinsurance contracts with the reinsurer. At the interim stage, date 1 , the insurers and the reinsurer receive some private signals about the payoffs of the insurance risks, while the outside investors receives no signal. Right after the signal is received, the insurers trade either an index futures with the uninformed outside investor, or a reinsurance contract with the reinsurer, as they planned at date 0 . At the final stage, date 2 , payoffs are realized and all signals become public.

More precisely the insurer $n(n=1, \ldots, N)$ has the utility function $E\left[-\exp \left(-\frac{1}{r_{I}} W\right)\right]$ over the consumption $W$ at date 2 , is endowed with an asset that has a payoff $z$ at date 2 , and receives a vector $S$ of information signals at date 1 . The reinsurer has the utility function $E\left[-\exp \left(-\frac{1}{r_{R}} W\right)\right]$ over the consumption $W$ at date 2 , receives the same vector $S$ of information signals that the insurers do at date 1 , but has no asset. The outside investor has the utility function $E\left[-\exp \left(-\frac{1}{r_{u}} W\right)\right]$ 
over the consumption $W$ at date 2, but has neither endowment of an asset nor an information signal.

For tractability we assume that $z_{n}$ is given by a product of two random variables $x_{n}$ and $e_{n}$, namely $z_{n}=e_{n} x_{n}$, where $x_{n}$ represents the per unit payoff of the $n$ 's insurance risk and $e_{n}$ represents the size, in terms of units, of the $n$ 's insurance risk. We also assume that

$$
x_{n}=x_{c}+\varepsilon_{n} .
$$

For each $n$, denote by $s_{n}$ a signal on $\varepsilon_{n}$. Define $e \equiv\left[e_{1}, \ldots, e_{N}\right]^{\top}, \varepsilon \equiv$ $\left[\varepsilon_{1}, \ldots, \varepsilon_{N}\right]^{\top}, x \equiv\left[x_{1}, \ldots, x_{N}\right]^{\top}$, and $s \equiv\left[s_{1}, \ldots, s_{N}\right]^{\top}$.The vector of information signals $S$ that the insurers and the reinsurer receives at date 1 is given by $S \equiv\left(s^{\top}, e^{\top}\right)^{\top}$.

All underlying random variables are normally distributed with 0 means, and are independent except that for each $n$,

$$
C\left[\varepsilon_{n}, s_{n}\right]=\rho \quad(\rho \neq 0) .
$$

We assume that $\operatorname{Var}\left[e_{n}\right]$ is the same for all $n$, that $\operatorname{Var}\left[\varepsilon_{n}\right]$ is the same for all $n$, and that $\operatorname{Var}\left[s_{n}\right]$ is the same for all $n$.

There are two kinds of possible contracts that the insurers choose to trade. One is an index futures contract with a payoff $F=\frac{1}{N} \sum_{n=1}^{N} x_{n}$. The other is reinsurance contracts with payoffs $x=\left(x_{1}, \ldots, x_{N}\right)^{\top}$. The insurers decide collectively whether they trade the index futures or the reinsurance contracts. In the former case, the insurers share their endowment risks with the uninformed non-insurance investor in the capital markets through trading the index futures. In the latter case, the insurers share their endowment risks with the equally informed reinsurer through the reinsurance market.

Note that although the investor in the capital markets is less informed than the insurers and the reinsurer, typically the capital markets is much larger than the reinsurance market in its size. Thus, with symmetric information, the aggregate investor of the larger capital market would be more risk tolerant than the reinsurer in the smaller reinsurance market.

\section{THE INDEX FUTURES}

We first investigate the case where the insurers trade the index futures with the outside investor in the capital market. Here, we assume that the reinsurer 
does not participate in trading the futures. We would like to know the condition under which bundling the insurers' endowment risks into an index futures facilitates risk sharing between the insurers and the outside investor.

Note that if the insurers and the outside investor have the same information about the risks that they trade, there is no benefit for creating an index futures for both sides. Trading each insurer's endowment risk separately provides better opportunities for risk sharing.

However, this is not the case for typical insurance markets, including CAT insurance. Usually, the outside non-insurance investor knows little about the risks that the insurance contracts deal with, while the insurers know them well. Asymmetric information is prevalent between the insiders and the outsider of the insurance markets.

Thus, we focus on the situation where each insurer's endowment risk cannot be traded separately with the outside investor because of adverse selection, but bundling these risks into an index futures mitigates the adverse selection problem so that the index futures can be traded between the insurers and the outside investor.

For this purpose, let us start with the hypothetical case where each insurer $n$ creates an insurance futures contract with the payoff $x_{n}$ aiming to trade it separately with the outside investor. We assume that each insurer does not trade the other insurers' contracts.

Denote by $\theta_{n}$ the position that the insurer $n$ takes. Each insurer $n$ tries to trade the futures $x_{n}{ }^{2}$ with the outside investor strategically i.e., taking account of the price impact of his position $\theta_{n}$. Let $\theta=\left(\theta_{1}, \ldots, \theta_{N}\right)^{\top}$. We assume that the price is given by a linear function

$$
P_{n}(\theta)=h_{n}+k \theta_{n}+l \sum_{m \neq n} \theta_{m} .
$$

The insurer $n$ 's date 2 wealth after trading this futures is given by

$$
W_{n}=e_{n} x_{n}+\theta_{n}\left(x_{n}-P_{n}(\theta)\right) \text {. }
$$

At date 1 , the insurer $n$ solves the following problem to obtain the optimal position $\theta_{n}$.

$$
\operatorname{Max}_{\theta_{n}}\left[-\exp \left(\frac{-1}{\gamma_{I}} W_{n}\right) \mid S\right]
$$

\footnotetext{
${ }^{2}$ Equivalently, we can assume that the contract is not a futures, that its price is paid at date 1 , and that there exists a riskless asset between date 1 and date 2 whose rate of return is normalized to one.
} 
Its first order condition is

$$
E\left[x_{n} \mid S\right]-h_{n}-2 k \theta_{n}-l \sum_{m \neq n} \theta_{m}-\frac{1}{\gamma_{I}}\left\{\operatorname{Var}\left[x_{n} \mid S\right] e_{n}+\operatorname{Var}\left[x_{n} \mid S\right] \theta_{n}\right\}=0
$$

and its second order condition is

$$
2 k+\frac{1}{\gamma_{I}} \operatorname{Var}\left[x_{n} \mid S\right]>0 .
$$

Note that the optimal $\theta_{n}$ 's are simultaneously determined. Define $q_{n}=E\left[x_{n} \mid S\right]-$ $\frac{1}{\gamma} \operatorname{Var}\left[x_{n} \mid S\right], Q=\left(q_{1}, \ldots, q_{N}\right)^{\top}$, and $H=\left(h_{1}, \ldots, h_{N}\right)^{\top}$. Denote by $I_{N}$ the $N \times N$ identity matrix and by $J_{N}$ the $N \times N$ matrix whose elements are all 1 . Then, if the second order conditions are satisfied for all $n$, then the vector of the insurers' optimal positions $\theta=\left(\theta_{1}, \ldots, \theta_{N}\right)^{\top}$ is given by

$$
\theta=\frac{1}{2 k+\frac{1}{\gamma_{I}} \operatorname{Var}\left[x_{n} \mid S\right]-l}\left\{I_{N}-\frac{l}{2 k+\frac{1}{\gamma_{I}} \operatorname{Var}\left[x_{n} \mid S\right]+(N-1) l} J_{N}\right\}(Q-H) .
$$

Denote by $\theta_{u n}$ the position that the outside investor $u$ takes in trading the $n$th futures. Let $\theta_{u}=\left(\theta_{u 1}, \ldots, \theta_{u N}\right)^{\top}$ and $x=\left(x_{1}, \ldots, x_{N}\right)^{\top}$. The outside investor is assumed to represent a large number of identical investors and hence behaves competitively. He has rational expectations and uses the observed prices to update beliefs about the payoff of the traded securities. Then, the outside investor's date 2 wealth after trading the futures is given by

$$
W_{u}=\theta_{u}^{\top}(x-P(\theta))
$$

where $p(\theta)=\left(p_{1}(\theta), \ldots, p_{N}(\theta)\right)^{\top}$. At date 1 , the outside investor solves the following problem to obtain the optimal position $\theta_{u}$.

$$
\operatorname{Max}_{\theta_{u}}\left[-\exp \left(\frac{-1}{\gamma_{u}} W_{u}\right) \mid \theta\right]
$$

Its first order condition is

$$
E[x \mid \theta]-P(\theta)-\frac{1}{\gamma_{u}} \operatorname{Var}[x \mid \theta] \theta_{u}=0
$$

and its second order condition is

$$
\frac{1}{\gamma_{u}} \operatorname{Var}[x \mid \theta]>0 \text {. }
$$


This second order condition is satisfied by assumption. Hence, the vector of the outside investor's optimal position is given by

$$
\theta_{u}=\gamma_{u} \operatorname{Var}[x \mid \theta]^{-1}\{E[x \mid \theta]-P(\theta)\} .
$$

A linear rational expectation equilibrium is a set $\left(P(\cdot), \theta, \theta_{u}\right)$ such that (a) $P(\cdot)$ is given by (3), (b) agents maximize, and (c) markets clear, that is $\theta+$ $\theta_{u}=0$. From the insurers' second order condition (4), we obtain the following condition for the individual insurance risks to be traded separately in the capital market:

\section{Lemma 1:}

An equilibrium exists if and only if

$$
J=\frac{1}{\gamma_{I}^{2}} \operatorname{Var}^{2}\left[x_{n} \mid s_{n}\right] \operatorname{Var}\left[e_{n}\right]-\frac{\operatorname{Cov}^{2}\left[\varepsilon_{n}, s_{n}\right]}{\operatorname{Var}\left[s_{n}\right]}>0 .
$$

Lemma 1 shows that if $J \leqq 0$, this economy fails to have an equilibrium. The first term of $J$ is related to the hedging demand of the informed insurers as indicated by its dependence on the degree of risk aversion. The second term is related to the informational motive for trading. An equilibrium exists if the former dominates the latter. If this is not the case, the adverse selection problem is so severe that no equilibrium exists.

In the following, we assume the following:

Assumption 1:

$$
J \leqq 0 .
$$

That is, we focus on the situation where each insurer $n$ cannot trade his own endowed insurance risk separately with the non-insurance outside investor because of the strong adverse selection between them.

One practical way to mitigate this adverse selection problem is to create an index of the average of the payoffs of the insurers' endowment risks and to create a futures contract whose payoff is determined by this index. (See Ganapati et. al. (1997), Kist and Meyers (1999), and Major (1999).) In this average index, it is expected that by the law of large number, each insurers' specific risks would be diversified enough, if the number of insurers is large enough. The index 
would depend largely on the market-wide common risk. Since informational asymmetry is much less for the market-wide common risk than for the insurers' specific risks, the adverse selection for the average index futures is much less than that for the individual insurance contracts.

Let $F=\frac{1}{N} \sum_{n=1}^{N} x_{n}$ be the payoff of the average index futures. Denote by $\theta_{F n}$ the position that the insurer $n$ takes in trading the index futures. Let $\theta_{F}=$ $\left(\theta_{F 1}, \ldots, \theta_{F N}\right)^{\top}$. Each insurer $n$ tries to trade the index futures $F$ strategically with the outside investor i.e., taking account of the price impact of his position $\theta_{F n}$. We assume that the price of the index futures is given by a linear function

$$
P_{F}(\theta)=h_{F}+k_{F} \sum_{n=1}^{N} \theta_{n}
$$

The insurer $n$ 's date 2 wealth after trading the index futures is given by

$$
W_{F n}=e_{n} x_{n}+\theta_{F n}\left(F-P_{F}(\theta)\right) \text {. }
$$

At date 1, the insurer $n$ solves the following problem to obtain the optimal position $\theta_{F n}$.

$$
\operatorname{Max}_{\theta_{F n}}\left[-\exp \left(\frac{-1}{\gamma_{I}} W_{F n}\right) \mid S\right]
$$

Its first order condition is

$$
E\left[x_{n} \mid S\right]-h_{F}-k_{F}\left\{2 \theta_{F n}+\sum_{m \neq n} \theta_{m}\right\}-\frac{1}{\gamma_{I}}\left\{\operatorname{Cov}\left[F, x_{n} \mid S\right] e_{n}+\operatorname{Var}[F \mid S] \theta_{F n}\right\}=0
$$

and its second order condition is

$$
2 k_{F}+\frac{1}{\gamma_{I}} \operatorname{Var}[F \mid S]>0 .
$$

Define $q_{F n}=E[F \mid S]-\frac{1}{\gamma_{I}} \operatorname{Cov}\left[F, x_{n} \mid S\right] e_{n}, Q_{F}=\left(q_{F 1}, \ldots, q_{F N}\right)^{\top}$, and $H_{F}=$ $\left(h_{F}, \ldots, h_{F}\right)^{\top}$. Note that $I_{N}$ is the $N \times N$ identity matrix and that $J_{N}$ is the $N \times N$ matrix whose elements are all 1 . If the second order conditions are satisfied for all $n$, then the vector of the insurers' optimal positions $\theta_{F}=\left(\theta_{F 1}, \ldots, \theta_{F N}\right)^{\top}$ is given by

$$
\theta_{F}=\frac{1}{k_{F}+\frac{1}{\gamma_{I}} \operatorname{Var}[F \mid S]}\left\{I_{N}-\frac{k_{F}}{(N+1) k_{F}+\frac{1}{\gamma_{I}} \operatorname{Var}[F \mid S]} J_{N}\right\}\left(Q_{F}-H_{F}\right) .
$$


Define $\theta_{F I} \equiv \sum_{n=1}^{N} \theta_{F n}$. Then, $\theta_{F I}$ is the aggregate position in the index futures by the insurers, and

$$
\theta_{F I}=\frac{1}{(N+1) k_{F}+\frac{1}{\gamma_{I}} \operatorname{Var}[F \mid S]}\left\{N E[F \mid S]-\frac{1}{\gamma_{I}} \operatorname{Cov}\left[F, x_{n} \mid S\right] \sum_{n=1}^{N} e_{n}-N h_{F}\right) .
$$

Denote by $\theta_{F u}$ the position that the outside investor $u$ takes in trading the index futures. The outside investor behaves competitively. He has rational expectations and uses the observed price to update beliefs about the payoff of the index futures. Then, the outside investor's date 2 wealth after trading the index futures is given by

$$
W_{F u}=\theta_{F}\left(F-P_{F}\left(\theta_{F}\right)\right)
$$

At date 1, the outside investor solves the following problem to obtain the optimal position $\theta_{F u}$.

$$
\operatorname{Max}_{\theta_{F u}}\left[-\exp \left(\frac{-1}{\gamma_{u}} W_{F u}\right) \mid \theta_{F}\right]
$$

Its first order condition is

$$
E\left[F \mid \theta_{F}\right]-P_{F}(\theta)-\frac{1}{\gamma_{u}} \operatorname{Var}\left[F \mid \theta_{F}\right] \theta_{F u}=0
$$

and its second order condition is

$$
\frac{1}{\gamma_{u}} \operatorname{Var}\left[F \mid \theta_{F}\right]>0
$$

This second order condition is satisfied by assumption. Hence, the vector of the outside investor's optimal position is given by

$$
\theta_{F u}=\gamma_{u} \operatorname{Var}\left[F \mid \theta_{F}\right]^{-1}\left\{E\left[F \mid \theta_{F}\right]-P_{F}(\theta)\right\} .
$$

A linear rational expectation equilibrium is a set $\left(P_{F}(\cdot), \theta_{F}, \theta_{F u}\right)$ such that (a) $P_{F}(\cdot)$ is given by (9), (b) agents maximize, and (c) markets clear, that is $\theta_{F}+\theta_{F u}=0$. From the insurers' second order condition (10), we obtain the following condition for the index futures to be traded: 


\section{Lemma 2:}

An equilibrium exists for the index futures market if and only if

$$
J_{F} \equiv \frac{1}{\gamma_{I}^{2}}\left\{(N-1) \operatorname{Var}[x]+\operatorname{Var}\left[x_{n} \mid s_{n}\right]\right\}^{2} \operatorname{Var}\left[e_{n}\right]-\frac{\operatorname{Cov}^{2}\left[\varepsilon_{n}, s_{n}\right]}{\operatorname{Var}\left[s_{n}\right]}>0 .
$$

Similarly to lemma 1 , the first term of $J_{F}$ is related to the hedging demand of the informed insurers for the index futures. The second term is related to the informational motive for trading. An equilibrium exists if the former dominates the latter. Comparing this lemma with lemma 1, we now obtain the following result:

\section{Proposition 1:}

Between the insurers and the outside investor, the average index futures is traded, while the individual insurance risks cannot be traded separately, if and only if

$$
\begin{aligned}
& \frac{1}{\gamma_{I}^{2}}\left\{(N-1) \operatorname{Var}\left[x_{c}\right]+\operatorname{Var}\left[x_{n} \mid s_{n}\right]\right\}^{2} \operatorname{Var}\left[e_{n}\right] \\
> & \frac{\operatorname{Cov}^{2}\left[\varepsilon_{n}, s_{n}\right]}{\operatorname{Var}\left[s_{n}\right]} \\
> & \frac{1}{\gamma_{I}^{2}} \operatorname{Var}^{2}\left[x_{n} \mid s_{n}\right] \operatorname{Var}\left[e_{n}\right]
\end{aligned}
$$

Hence, there is a case where creating an index futures whose payoff is the average of the insurers endowment risks mitigates the adverse selection enough for the index futures to be traded, although each insurer's individual insurance risk cannot be traded with the uninformed outside investor.

Observe that if $N=1$, the condition $J_{F}>0$ is equivalent to $J>0$. Observe also that the larger $N$ is, the weaker the restriction $J_{F}>0$ is. Thus, the futures of each insurer's individual risk is a special case of the average index futures, and as the number of the insurers in the average index increases, the index futures is more likely to be traded. 
Proposition 1 also shows that for the average-indexing to work, it is necessary that $\operatorname{Var}\left[x_{c}\right]>0$. That is, if the insurers' endowment payoffs are independent, averaging is useless to mitigate the adverse selection problem. The larger the portion of the (non-informational) common part $x_{c}$ of the payoffs $x_{n}$ 's is (in terms of their variances), the more effective the averaging is for mitigating the adverse selection.

\section{THE REINSURANCE MARKETS}

Traditionally, insurance risks are traded in reinsurance markets. That is, after originating insurance contracts and bearing risks of customers, the insurers reallocate such risks among themselves and reinsurers. Lloyd's is a notable example. Munich Re. and Swiss Re. are some of the representative reinsurers.

Participants in the reinsurance markets are presumably professionals in insurance. They know equally well about insurance risks that they trade. At least, asymmetric information is much less among insurers and reinsurers than between insurers and non-insurance outside investors in the capital markets. Adverse selection problem about insurance risks is small in the reinsurance markets.

However, the size of the reinsurance markets is much smaller than that of the capital markets. This limits the capacity of the reinsurance markets to bear the insurance risks, especially those associated with large natural disasters. In fact, catastrophic losses by earthquakes and typhoons in 1990's, in conjunction with the slump in business by Lloyd's, caused the shortage of capacity of reinsurance, which resulted in the sharp rise of the reinsurance premiums. Naturally, the insurers looked for the way that enabled them to trade their insurance risks with the non-insurance outside investors in the capital markets. The CAT index futures is one of the inventions.

Thus, we model the reinsurance markets as one representative reinsurer who has the same information as the insurers, but is less risk tolerant than the representative non-insurance outside investor. We consider the idealized reinsurance markets where the insurers and the reinsurer have the symmetric information, trade their risks competitively, and attain the optimal risk allocation.

In this idealized reinsurance markets, the insurance risks $x=\left(x_{1}, \ldots, x_{N}\right)^{\top}$ of the insurers are traded. Denote by $\theta_{R n}=\left(\theta_{R n 1}, \ldots, \theta_{R n N}\right)^{\top}$ the position that the insurer $n$ takes in the reinsurance markets. Each insurer $n$ trades the futures $x_{n}$ competitively. Let $P_{R}=\left(P_{R 1}, \ldots, P_{R N}\right)^{\top}$ be the price of the reinsurance 
futures contracts. Then, the date 2 wealth of the insurer $n$ after trading in the reinsurance markets is given by

$$
W_{R n}=e_{n} x_{n}+\theta_{R n}^{\top}\left(x-P_{R}\right) .
$$

It is more convenient to use the gross position $\phi_{R n}$ that is defined by $\phi_{R n} \equiv$ $\left(\theta_{R 1}, \ldots, \theta_{R n}+z_{n}, \ldots, \theta_{R N}\right)^{\top}$ for all $n$. In terms of the gross futures position, at date 1 , the insurer $n$ solves the following problem to obtain the optimal position $\phi_{R n}$.

$$
\operatorname{Max}_{\phi_{R n}}\left[-\exp \left(\frac{-1}{\gamma_{I}} W_{R n}\right) \mid S\right]
$$

Its first order condition is

$$
E[x \mid S]-P_{R}-\frac{1}{\gamma_{I}} \operatorname{Var}[x \mid S] \phi_{n}=0
$$

and its second order condition is

$$
\operatorname{Var}[x \mid S]>0 .
$$

Since the second order condition is satisfied by assumption, the insurer $n$ 's optimal gross position $\phi_{R n}=\left(\phi_{R 1}, \ldots, \phi_{R N}\right)^{\top}$ is given by

$$
\phi_{R n}=\gamma_{I} \operatorname{Var}[x \mid S]^{-1}\left\{E[x \mid S]-P_{R}\right\} .
$$

Denote by $\theta_{R E}=\left(\theta_{R E 1}, \ldots, \theta_{R E N}\right)^{\top}$ the position that the reinsurer takes. The reinsurer has the same information as the insurers, and trade the reinsurance contracts competitively. Then, the reinsurer's date 2 wealth after trading the reinsurance contracts is given by

$$
W_{R E}=\theta_{R E}^{\top}\left(x-P_{R}\right)
$$

At date 1 , the reinsurer solves the following problem to obtain the optimal position $\theta_{R E}$.

$$
\operatorname{Max}_{\theta_{R E}}\left[-\exp \left(\frac{-1}{\gamma_{R E}} W_{R E}\right) \mid S\right]
$$

Its first order condition is

$$
E[x \mid S]-P_{R}-\frac{1}{\gamma_{R E}} \operatorname{Var}[x \mid S] \theta_{R E}=0
$$


and its second order condition is

$$
\operatorname{Var}[x \mid S]>0 .
$$

Since the second order condition is satisfied by assumption, the reinsurer's optimal position is given by

$$
\theta_{R E}=\gamma_{R E} \operatorname{Var}[x \mid S]^{-1}\left\{E[x \mid S]-P_{R}\right\} .
$$

Note that since the reinsurer has no endowment, this position $\theta_{R E}$ is equal to the gross position $\phi_{R E \text {. }}$

Let $e=\sum_{n=1}^{N} e_{n}$. In an equilibrium, $\sum_{n=1}^{N} \phi_{R n}+\phi_{R E}=e$. From this marketclearing condition, we obtain the equilibrium price $P_{R}$ as follows:

$$
P_{R}=E[x \mid S]-\frac{1}{N \gamma_{I}+\gamma_{R E}} \operatorname{Var}[x \mid S] e
$$

Hence, the investor $n$ 's equilibrium gross position is given by

$$
\phi_{R n}=\frac{\gamma_{I}}{N \gamma_{i}+\gamma_{R E}} e,
$$

and the reinsurer's equilibrium gross position is given by

$$
\phi_{R n}=\frac{\gamma_{R E}}{N \gamma_{i}+\gamma_{R E}} e
$$

That is, in an equilibrium in the idealized reinsurance markets, the aggregated insurance risks $e$ is allocated to the market participants according to their risk tolerance..

\section{CREATION OF THE INDEX FUTURES BY THE INSURERS}

Traditionally, the insurance risks that the individual insurers bear for their customers are reallocated among the insurers and the reinsurers through the reinsurance markets. In 1990's, however, several huge natural disasters hit the insurance industry with huge amount of insurance payments for them, which shrank the capacity of the reinsurance markets to bear suck risks. The reinsurance premiums soared, and the insurers were forced to invent the means to share their insurance risks outside the reinsurance markets. The CAT index futures is among them. 
In this section, we consider such situation where the insurers create the index futures to share their insurance risks with the outside investors i.e., the capital markets, instead of the reinsurance markets. We would like to know under what condition the insurers wish to have such index futures rather than reinsurance contracts.

For this purpose, we assume that the insurers trade either the index futures or the reinsurance contracts, and then compare the insurer's ex-ante utility levels between when the index futures is traded and when reinsurance contracts are traded.

We first obtain the ex-ante utility level for the index futures.

Lemma 3:

When the index futures is traded, the ex-ante utility of the insurer $n$ is given by

$$
\begin{aligned}
& E\left[u_{I}\left(W_{F n}\right)\right] \\
= & -\left[\left(1-\frac{2}{\gamma_{I}^{2}} \operatorname{Var}\left[x_{n}\right] \operatorname{Var}\left[e_{n}\right]\right)+\frac{2}{\gamma_{I}} \operatorname{Var}\left[\theta_{F n}\right] \alpha_{3}\left(1-\frac{2}{\gamma_{I}^{2}} \operatorname{Var}\left[x_{n}\right] \operatorname{Var}\left[e_{n}\right]\right)\right. \\
& \left.+\frac{2}{\gamma_{I}} \operatorname{Var}\left[e_{n}\right] \alpha_{3}\left\{2 \operatorname{Cov}\left[x_{n}, s_{n}\right] \alpha_{0} \alpha_{2}+\frac{1}{\gamma_{I}} \operatorname{Cov}^{2}\left[x_{n}, s_{n}\right] \alpha_{0}^{2}+\frac{1}{\gamma_{I}} \operatorname{Var}\left[e_{n}\right] \operatorname{Var}\left[x_{n}\right] \alpha_{2}^{2}\right\}\right]^{\frac{-1}{2}}
\end{aligned}
$$

where

$$
\begin{aligned}
\alpha_{0} & \equiv \frac{1}{(N+1) k_{F}+\frac{1}{\gamma_{I}} \operatorname{Var}[F \mid S]} \frac{\operatorname{Cov}\left[x_{n}, s_{n}\right]}{\operatorname{Var}\left[s_{n}\right]} \frac{1}{N} \\
\alpha_{1} & \equiv \frac{1}{k_{F}+\frac{1}{\gamma_{I}} \operatorname{Var}[F \mid S]} \frac{k_{F}}{(N+1) k_{F}+\frac{1}{\gamma_{I}} \operatorname{Var}[F \mid S]} \frac{1}{\gamma_{I}} \operatorname{Cov}\left[F, x_{n} \mid S\right] \\
\alpha_{2} & \equiv \frac{1}{k_{F}+\frac{1}{\gamma_{I}} \operatorname{Var}[F \mid S]} \frac{N k_{F}+\frac{1}{\gamma_{I}} \operatorname{Var}[F \mid S]}{(N+1) k_{F}+\frac{1}{\gamma_{I}} \operatorname{Var}[F \mid S]} \frac{1}{\gamma_{I}} \operatorname{Cov}\left[F, x_{n} \mid S\right] \\
\alpha_{3} & \equiv k_{F}+\frac{1}{2 \gamma_{I}} \operatorname{Var}[F \mid S] \\
\operatorname{Var}\left[\theta_{F n}\right] & =N \alpha_{0}^{2} \operatorname{Var}\left[s_{n}\right]+(N-1) \alpha_{1}^{2} \operatorname{Var}\left[e_{n}\right]+\alpha_{2}^{2} \operatorname{Var}\left[e_{n}\right]
\end{aligned}
$$

We next obtain the ex-ante utility level for the reinsurance contracts. 


\section{Lemma 4:}

When the reinsurance contracts are traded, the ex-ante utility of the insurer $n$ is given by

$$
\begin{aligned}
E & {\left[u_{I}\left(W_{R n}\right)\right] } \\
=- & {\left[1-\frac{1}{\gamma_{I}^{2}} \operatorname{Var}\left[x_{n}\right] \operatorname{Var}\left[e_{n}\right]+\left\{\frac{1}{\gamma_{I}^{2}}-\frac{(2 N-1) \gamma_{I}+2 \gamma_{R}}{\gamma_{I}\left(N \gamma_{I}+\gamma_{R}\right)^{2}}\right\} \operatorname{Var}\left[\varepsilon_{n} \mid s_{n}\right] \operatorname{var}\left[e_{n}\right]\right.} \\
& +\left\{\frac{1}{\gamma_{I}^{2}}-\frac{(2 N-1) \gamma_{I}+2 \gamma_{R}}{\gamma_{I}\left(N \gamma_{I}+\gamma_{R}\right)^{2}}-\frac{\frac{\operatorname{Var}\left[e_{n}\right]}{\left(N \gamma_{I}+\gamma_{R}\right)^{2}}(N-1) \operatorname{Var}\left[e_{n}\right]}{1+\frac{\operatorname{Var}\left[e_{n}\right]}{\left(N \gamma_{I}+\gamma_{R}\right)^{2}}\left\{\operatorname{Var}\left[\varepsilon_{n} \mid s_{n}\right]+(N-1) \operatorname{Var}\left[e_{n}\right]\right\}}\right\} \\
& \left.\times \frac{\left\{(N-1) \gamma_{I}+\gamma_{R}\right\}^{2}}{\gamma_{I}^{2}\left(N \gamma_{I}+\gamma_{R}\right)^{2}} \operatorname{Var}\left[x_{c}\right] \operatorname{Var}\left[e_{n}\right]\right]^{\frac{-1}{2}} \\
\times & {\left[\left\{1+\frac{\operatorname{Var}\left[e_{n}\right]}{\left(N \gamma_{I}+\gamma_{R}\right)^{2}}\left(\operatorname{Var}\left[\varepsilon_{n} \mid s_{n}\right]+(N-1) \operatorname{Var}\left[e_{n}\right]\right)\right\}\left\{1+\frac{\operatorname{Var}\left[e_{n}\right]}{\left(N \gamma_{I}+\gamma_{R}\right)^{2}} \operatorname{Var}\left[\varepsilon_{n} \mid s_{n}\right]\right\}^{N-2}\right]^{\frac{2}{2}} }
\end{aligned}
$$

By comparing both utility levels, we can find when the insurers want the index futures.

\section{Proposition 2:}

The insurers wish to create an index futures, if and only if

$$
E\left[u_{I}\left(W_{F n}\right)\right]>E\left[u_{I}\left(W_{R n}\right)\right]
$$

The following numerical example describes the situation shown in this proposition. We take $\operatorname{Var}\left[x_{c}\right]=\operatorname{Var}\left[\varepsilon_{n}\right]=\operatorname{Var}\left[e_{n}\right]=1, \operatorname{Cov}\left[\varepsilon_{n}, s_{n}\right]=0.6, \gamma_{I}=\gamma_{u}=$ 5 . The number of insurers $N$ varies from 1 to 12. The coefficient of risk tolerance $\gamma_{R}$ of the reinsurer varies from 0.5 to 1 .

In this situation, by Proposition 1, we know that the individual insurer's own risk cannot be traded with the uninformed outside investor due to the strong adverse selection. Indeed, $N$, the number of the insurers, or the number of the insurers' risks included in the index futures, should be larger than or equal to 3 for the index futures to be traded. This is why the graph of figure 1 starts from $N=3$.

In general, the larger $N$ is, the less is the adverse selection in trading the index futures due to the diversification of the private risks. This makes it easier for the insurers to trade the index futures with the uninformed outside investors. However, this also increases the basis risks that the insurers face in trading the 
futures. The benefit of trading the index futures is determined by the trade-off between the decrease of the adverse selection and the increase of the basis risks. In this example, the former is more effective than the latter so that the utility of the insurer increases as $N$ increases. $^{3}$

\section{[Insert Fig. 1]}

On the other hand, the benefit of using the reinsurance market is determined by the reinsurer's risk tolerance $\gamma_{R}$. The larger $\gamma_{R}$ is, the more risk hedge the insurers have from the reinsurance market. The following graph in figure 2 shows this situation. ${ }^{4}$

[Insert Fig. 2]

For the insurers, whether to use the CAT index futures or the reinsurance markets depends on which gives them the better hedging opportunities. Figure 3 shows the difference between the utility levels obtained through trading the index futures and that through the reinsurance market.

Take, for example, the case where the reinsurer's coefficient $\gamma_{R}$ of risk tolerance is equal to 0.5. In this case, since the risk tolerance of the uninformed outside investor is much larger, despite the adverse selection, the index futures provides better hedging opportunity to the insurers when the number $N$ of the insurers is small. As $N$ increases, since the insurers share the insurance risks through reinsurance, the reinsurance market provides the better hedging opportunity than the index futures.

Take also the case where the number $N$ of the insurers is 3 . As the reinsurer's coefficient $\gamma_{R}$ of risk tolerance increases, though $\gamma_{R}$ is much smaller than $\gamma_{u}$, the risk tolerances of the uninformed outside investor, the reinsurance market becomes more attractive than the index futures to the insurers. This is because the index futures suffers from the adverse selection, while the reinsurance market does not.

\footnotetext{
${ }^{3}$ Note that in this example, as $N$ increases, the number of the insureres increases, and so the number of the traders in the futures market also increases. Since the calculated utility levels are affected by the change of the number of market participants, we need to be careful to interpret the effect of increasing $N$. Also, note that the reinsurer's risk tolerance does not affect the utility het because the reinsurer is assumed not to trade thr index futures.

${ }^{4}$ Note that in this model. we assume that the insurers bear the risks of the other insurers through the reinsurance market. This assumption tends to make the risk allocation through the reinsurance market more efficient than that throught the index futures, and hence the utility levels from the reinsurance tend to be larger than those from trading the index futures in this example.
} 
Recall that in this example, the index futures cannot be traded when $N=1$ and 2. Thus, the insurers use the reinsurance market when $N=1$ and 2 , the CAT index futures when $N=3$ to 5 if $\gamma_{R}$ is sufficiently small, and again the reinsurance market when $N$ is large enough.

\section{[Insert Fig. 3]}

\section{CREATION OF THE INDEX FUTURES BY THE EXCHANGE}

Although the CAT index futures is created mainly for the benefit of the insurers, it is the exchange who indeed creates the futures and who may have a different objective from the insurers. In this section, we look into this possibility. We assume that the exchange decides, ex-ante, whether to create the index futures depending on its expected trading volume.

Lemma 5:

The expected volume of the index futures is given by

$$
E V_{F}=\sqrt{\frac{2}{\pi}}\left[\alpha_{0}^{2} N \operatorname{Var}\left[s_{n}\right]+\alpha_{1}^{2}(N-1) \operatorname{Var}\left[e_{n}\right]+\alpha_{2}^{2} \operatorname{Var}\left[e_{n}\right]\right]^{\frac{1}{2}} .
$$

Also, the normalized expected volume of the index futures is given by

$$
N E V_{F}=E V_{F} \times \sqrt{\operatorname{Var}\left[x_{c}\right]+\frac{1}{N} \operatorname{Var}\left[\varepsilon_{n}\right]}
$$

We consider the normalized expected volume in order to keep the variance of the payoff of the normalized index futures equal to unity, which enables us to compare more accurately the expected volumes among the index futures with different $N$ 's.

The following numerical example shows that for some parameter values, increase in the number $N$ of the insurers in the index leads to decrease of both the expected and the normalized expected trading volume. We take $\operatorname{Var}\left[x_{c}\right]=$ $\operatorname{Var}\left[\varepsilon_{n}\right]=\operatorname{Var}\left[e_{n}\right]=1, \operatorname{Cov}\left[\varepsilon_{n}, s_{n}\right]=0.6, \gamma_{I}=\gamma_{u}=5$. The number of insurers $N$ varies from 1 to 5 . The green line shows how the expected trading volume changes as $N$ increases. The blue line shows the normalized expected trading volume, and the red line shows the insurer's utility level +1 . 


\section{[Insert Fig. 4]}

Combined with the discussion in section 3, this observation has an important implication, which we states as the following proposition:

Proposition 3:

In some situation, while it is necessary to have the number $N$ of the insurers in the index large enough to mitigate the adverse selection and encourage the outside investor to trade the index futures, it at the same time may reduce the (normalized) expected trading volume and discourage the exchange to create such index futures.

Thus, creating an index futures, though it is a useful device for mitigating adverse selection, may not be a useful device for the exchange to obtain profitable opportunities from creating the futures. It is possible that this is a part of the reason why the CAT index futures have had such thin markets and have never been successful, though their creation is a meaningful step to open a path of additional risk transfer from the reinsurance markets to the capital markets.

\section{CONCLUSIONS}

We investigated the conditions under which an average index futures of several insurance risks can be traded in the presence of asymmetric information. We found that even when each risks cannot be traded because of strong adverse selection, averaging these risks may mitigate the adverse selection enough so that the index futures can be traded, if the number of the risks included in averaging is large enough. However, we also found that averaging may reduce the attractiveness of the futures for both the insurers and the exchange. This may be a part of the reason why the CAT index futures are so unsuccessful, despite its clear theoretical importance as a new tool to transfer insurance risks to the capital markets.

For the ease of the analysis, we have investigated only the cases where the insurers trade either the index futures with the outside non-insurance investor or the reinsurance contracts with the reinsurer and where the reinsurance markets are idealized in that the insurers and the reinsurer can trade all reinsurance contracts with no frictions. Examining the case where the insurers can trade only the limited kinds of reinsurance contracts is a possible extension of the analysis. 
Finally, though we have just compared the use of the capital markets and that of the reinsurance markets from the insurers' viewpoint, they indeed interact with each other. Allowing the reinsurer to trade both the reinsurance contracts and the index futures at the same time may clarify the role of the reinsurer as an intermediary of the insurance risks among several markets. This is an immediate task in further research.

\section{REFERENCES}

1. Allen, F. and D. Gale (1994), Financial Innovation and Risk Sharing, MIT Press, Cambridge MA, USA.

2. Bhattacharya, U., P. J. Reny, and M. Spiegel (1995), Destructive Interference in an Imperfectly Competitive Multi-Security Market, Journal of Economic Theory, 65, 136-170.

3. Bhattacharya, U. and M. Spiegel (1991), Insiders, Outsiders, and Market Breakdowns, Review of Financial Studies, 4, 255-282.

4. DeMarzo, P. and D. Duffie (1999), A Liquidity-Based Model of Security Design, Econometrica, (1999) 67, 65-90.

5. Duffie, D. and R. Rahi (1995), Financial Innovation and Security Design, Journal of Economic Theory, 65, 1-42.

6. Ganapati, S., M. Retik, P. Puleo, and B. Starr (1997), Catastrophe-Linked Securities, Chapter 20 in Handbook of Structured Financial Products," ed. by F. Fabozzi (1998) Frank J. Fabozzi Associates, New Hope, Pennsylvania, USA.

7. Kist, F. O. and G. Meyers (1999), Evaluating the effectiveness of indexbased insurance derivatives in hedging property/casualty insurance transaciton, American Academy of Actuaries Index Securitization Task Force.

8. Major, J. A. (1999), Index Hedge Performance: Insurer Market Penetration and Basis Risk, Chapter 10 in The Financing of Catastrophe Risk," ed. by K. A. Froot, The University of Chicage Press, Chicago, Illinois, USA. 
9. Marin, J. M. and R. Rahi (1999), Speculative Securities, Economic Theory, 14, 653-668.

10. Ohashi, K. (1995), Endogenous Determination of the Degree of MarketIncompleteness in Futures Innovation, Journal of Economic Theory, 65, 198-217.

11. Rahi, R. (1996), Adverse Selection and Security Design, Review of Economic Studies, 63, 287-300.

12. Subrahmanyam, A. (1991), A Theory of Trading in Stock Index Futures, Review of Financial Studies 4, 17-51. 
APPENDIX : Key mathematical results.

Math. Lemma 1:

Let $I_{N}$ be the $N \times N$ identity matrix, $J_{N}$ be the $N \times N$ matrix with all elements equal to unity, and $a$ and $b$ be scalars where $a \neq 0$. Then,

$$
\left(a I_{N}+b J_{N}\right)^{-1}=\frac{1}{a}\left(I_{N}-\frac{b}{a+b N} J_{N}\right) .
$$

Proof of Math. Lemma 1:

Direct computation.||

Math. Lemma 2:

Let $A$ be a symmetric $N \times N$ matrix, $B$ be an $N \times 1$ vector, and $C$ be a scalar. Suppose that $e \sim N(0, \Sigma)$. Then,

$$
E\left[\exp \left(e^{\top} A e+B^{\top} e+C\right)\right]=\left|I_{N}-2 \Sigma A\right|^{\frac{-1}{2}} \exp \left(\frac{1}{2} B^{\top}\left(I_{N}-2 \Sigma A\right)^{-1} \Sigma B+C\right)
$$

if and only if $I_{N}-2 \Sigma A$ is positive definite.

Proof of Math.Lemma 2:

$$
\begin{aligned}
& E\left[\exp \left(e^{\top} A e+B^{\top} e+C\right)\right] \\
= & \int_{R^{N}} \exp \left(e^{\top} A e+B^{\top} e+C\right)(2 \pi)^{\frac{-N}{2}}|\Sigma|^{\frac{-1}{2}} \exp \left(\frac{-1}{2} e^{\top} \Sigma^{-1} e\right) d e \\
= & \int_{R^{N}}(2 \pi)^{\frac{-N}{2}}|\Sigma|^{\frac{-1}{2}} \exp \left[\frac{-1}{2}(e-H)^{\top}\left(\Sigma^{-1}-2 A\right)(e-H)+\frac{1}{2} B^{\top}\left(\Sigma^{-1}-2 A\right)^{-1} B+C\right] d e \\
= & |\Sigma|^{\frac{-1}{2}}\left|\left(\Sigma^{-1}-2 A\right)^{-1}\right|^{\frac{-1}{2}} \exp \left[\frac{1}{2} B^{\top}\left(\Sigma^{-1}-2 A\right)^{-1} B+C\right] \\
= & \left|I_{N}-2 \Sigma A\right|^{\frac{-1}{2}} \exp \left(\frac{1}{2} B^{\top}\left(I_{N}-2 \Sigma A\right)^{-1} \Sigma B+C\right)
\end{aligned}
$$

where $H=\left(\Sigma^{-1}-2 A\right)^{-1} B$. $\|$ 


\section{Proof of Lemma 1:}

Since $\theta_{u}+\theta=0$ in equilibrium, we have $H=0$,

$$
\begin{aligned}
k & =\frac{1}{1-2 \frac{\operatorname{Cov}\left[x_{n}, q_{n}\right]}{\operatorname{Var}\left[q_{n}\right]}}\left\{\frac{\operatorname{Cov}\left[x_{n}, q_{n}\right]}{\operatorname{Var}\left[q_{n}\right]} \frac{1}{\gamma_{I}} \operatorname{Var}\left[x_{n} \mid s_{n}\right]+\frac{1}{\gamma_{u}} \operatorname{Var}\left[x_{n} \mid q_{n}\right]\right\}, \text { and } \\
l & =\frac{1}{1-\frac{\operatorname{Cov}\left[x_{n}, q_{n}\right]}{\operatorname{Var}\left[q_{n}\right]}} \frac{1}{\gamma_{u}} \operatorname{Var}\left[x_{n}\right] .
\end{aligned}
$$

Substituting them, the second order condition of the insurers will be

$$
\frac{1}{1-2 \frac{\operatorname{Cov}\left[x_{n}, q_{n}\right]}{\operatorname{Var}\left[q_{n}\right]}}\left\{\frac{1}{\gamma_{I}} \operatorname{Var}\left[x_{n} \mid s_{n}\right]+\frac{2}{\gamma_{u}} \operatorname{Var}\left[x_{n} \mid q_{n}\right]>0,\right.
$$

which is satisfied if and only if

$$
1-2 \frac{\operatorname{Cov}\left[x_{n}, q_{n}\right]}{\operatorname{Var}\left[q_{n}\right]}>0
$$

Calculation shows that this is equivalent to

$$
\frac{1}{\gamma_{I}^{2}} \operatorname{Var}^{2}\left[x_{n} \mid s_{n}\right] \operatorname{Var}\left[e_{n}\right]-\frac{\operatorname{Cov}^{2}\left[x_{n}, q_{n}\right]}{\operatorname{Var}\left[q_{n}\right]}>0 . \quad \|
$$

Proof of Lemma 2:

Similar to the proof of Lemma 1. I

Proof of Proposition 1:

Clear from Lemma 1 and 2. $\|$

Proof of Lemma 3:

Direct calculation shows that the insurer's utility $E\left[u_{I}\left(W_{F n}\right)\right]$ is given by

$$
E\left[u_{I}\left(W_{F n}\right)\right]=E\left[-\exp \left(\frac{-1}{\gamma_{I}} \xi^{\top} A_{F} \xi\right)\right]
$$


where

$$
\begin{aligned}
& \xi= {\left[\begin{array}{c}
s_{n} \\
e_{n} \\
\theta_{n}
\end{array}\right], } \\
& A_{F}= {\left[\begin{array}{lll}
0 & \frac{1}{2} \frac{\operatorname{Cov}\left[x_{n}, s_{n}\right]}{\operatorname{Var}\left[s_{n}\right]} & 0 \\
\frac{1}{2} \frac{\operatorname{Cov}\left[x_{n}, s_{n}\right]}{\operatorname{Var}\left[s_{n}\right]} & \frac{-1}{2 \gamma_{I}} \operatorname{Var}\left[x_{n} \mid s_{n}\right] & 0 \\
0 & 0 & \alpha_{3}
\end{array}\right], \text { and } } \\
& \theta_{n}=\alpha_{0} \sum_{m=1}^{N} s_{n}+\alpha_{1} \sum_{m \neq n}^{N} e_{n}-\alpha_{2} e_{n} .
\end{aligned}
$$

Applying Math. Lemma 2, we obtain the desired result. ||

Proof of Lemma 4:

Similar to the proof of Lemma 3. $\|$

Proof of Lemma 5:

Note that

$$
\theta_{n}=\alpha_{0} \sum_{m=1}^{N} s_{n}+\alpha_{1} \sum_{m \neq n}^{N} e_{n}-\alpha_{2} e_{n} .
$$

thus, $\theta_{n}$ is normally distributed with mean equal to zero. The expected value of the absolute value of a normally distributed random variable with mean zero is well known. Apply this formula to $\theta_{n}$ we obtain the desired result. ||

Proof of Proposition 3:

Clear from the numerical example. $\|$ 


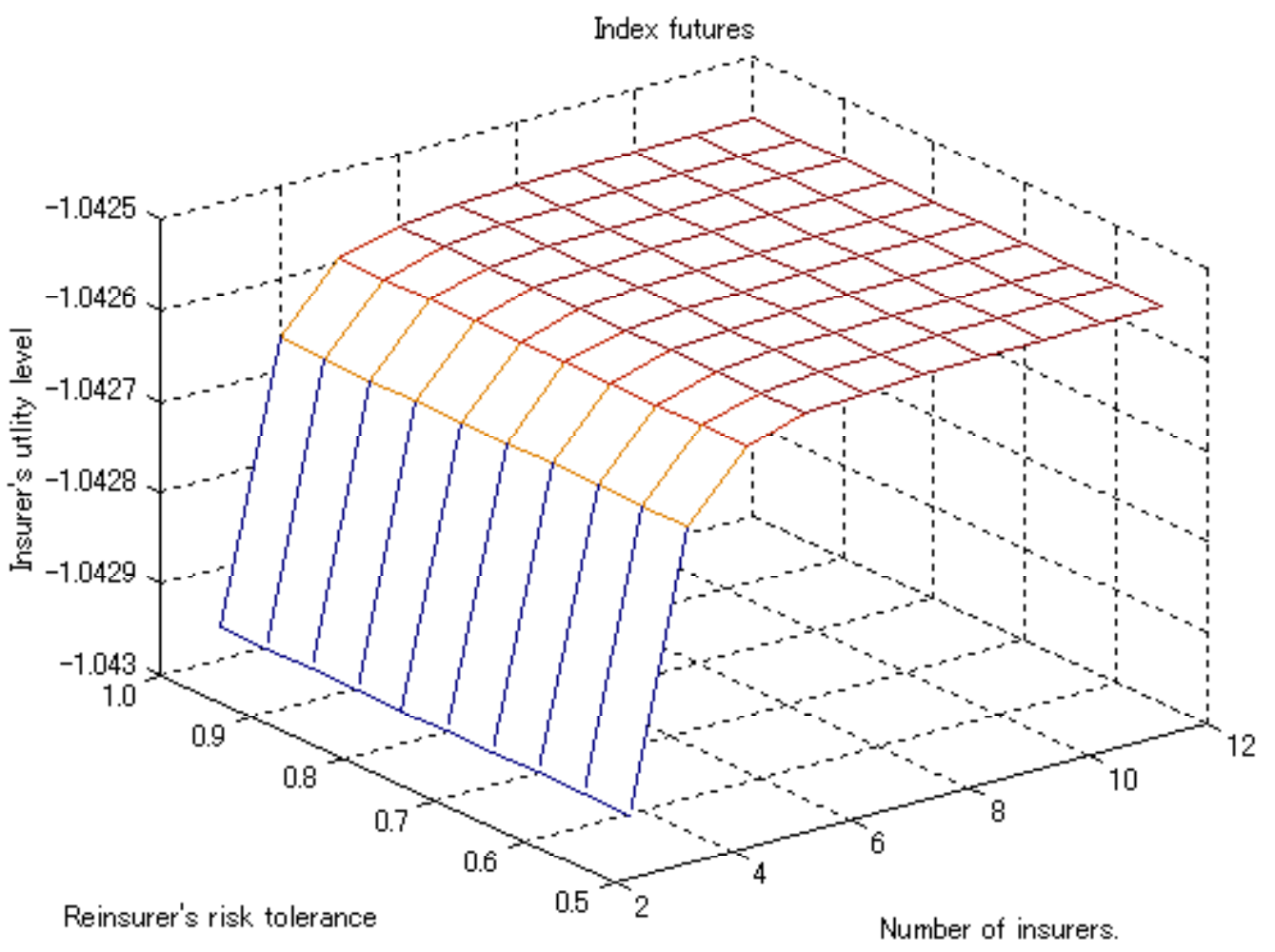

Figure 1: 


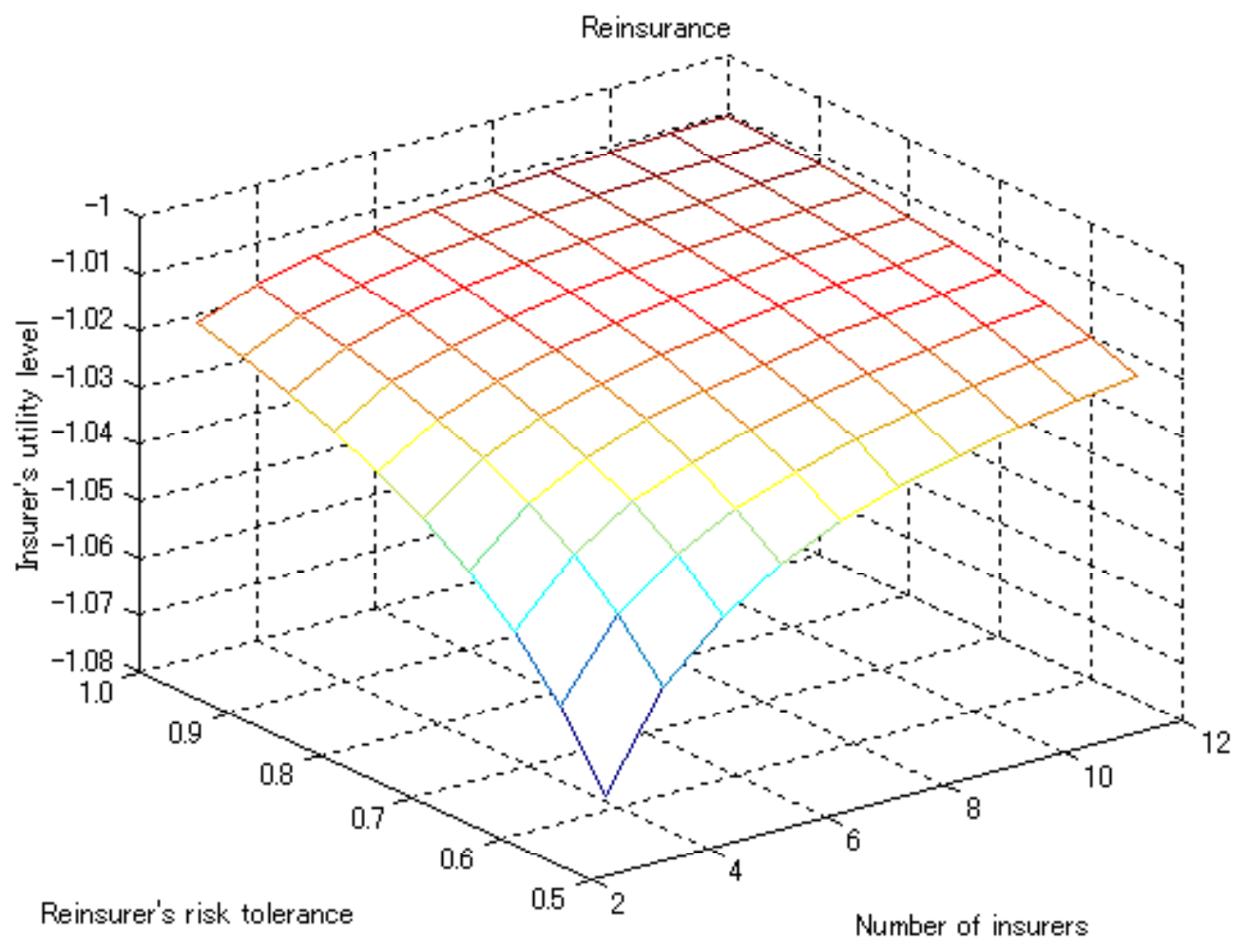

Figure 2: 


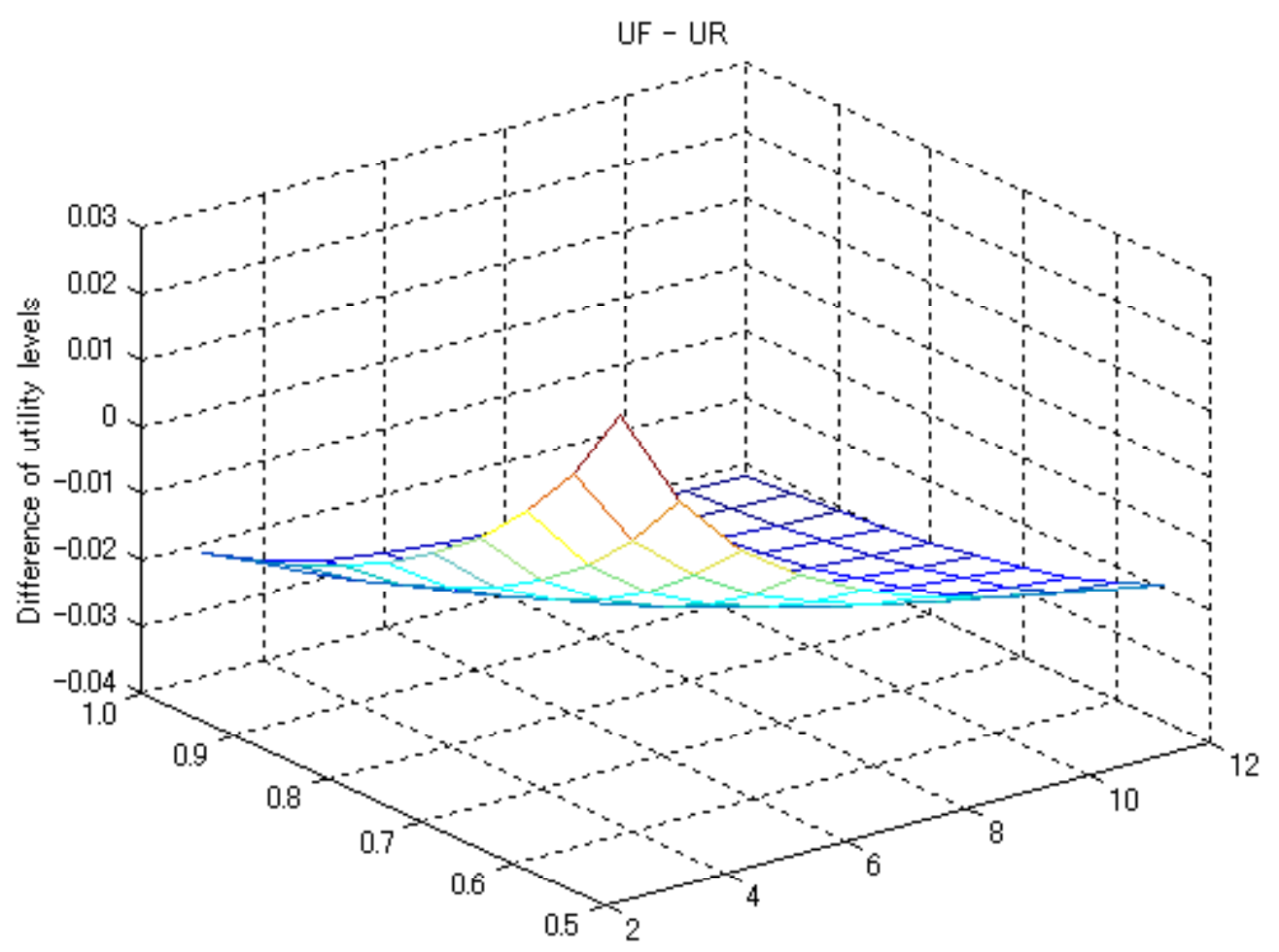

Figure 3: 


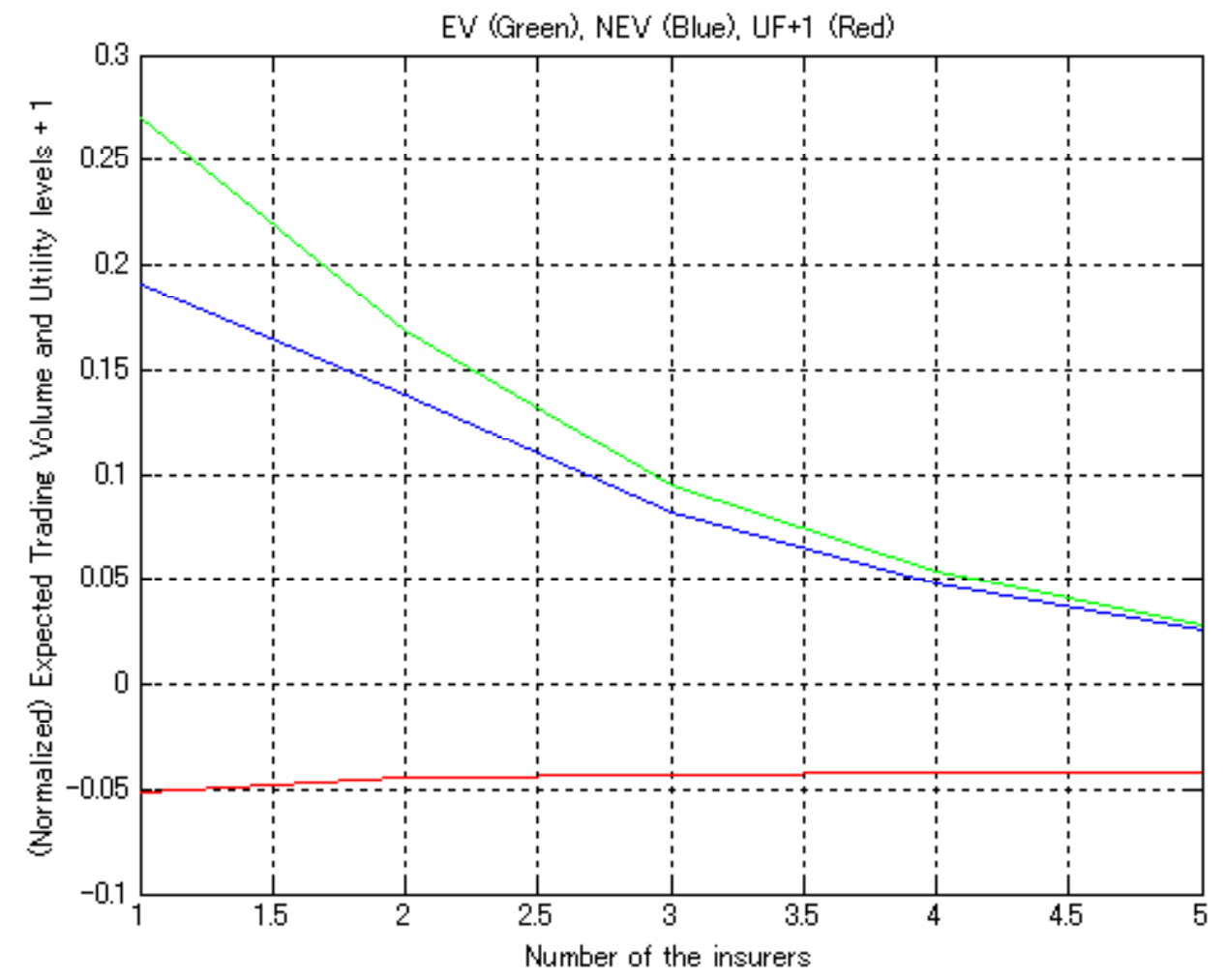

Figure 4: 